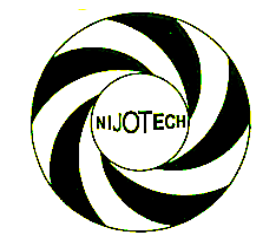

Nigerian Journal of Technology (NIJOTECH)

Vol. 39, No. 3, July 2020, pp. $\mathbf{8 0 0} \mathbf{- 8 0 6}$

Copyright@ Faculty of Engineering, University of Nigeria, Nsukka

Print ISSN: 0331-8443, Electronic ISSN: 2467-8821

www.nijotech.com

http://dx.doi.org/10.4314/njt.v39i3.20

\title{
ACIDIC LEACHING OF IRON FROM KAOJE GOETHITE ORE BY HYDROCHLORIC ACID: KINETICS MODELLING
}

\author{
K. I. Ayinla1,* , A. A. Baba ${ }^{2}$, S. Girigisu ${ }^{3}$, O. S. Bamigboye ${ }^{4}$, B. C. Tripathy ${ }^{5}$, \\ A. S. Ibrahim ${ }^{6}$ and S. O. Azeez ${ }^{7}$

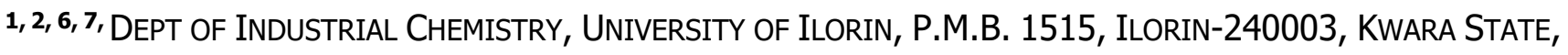 \\ NIGERIA. \\ 3, Dept. of Science Laboratory Technology, Federal Polytechnic Offa, P.M.B 420 Offa, Kwara State, \\ NIGERIA. \\ 4,7, Dept of Chemical, Geological and Physical Sciences, KWara State Univ. Malete, P.M.B. 1530, \\ ILORIN, KWARA STATE, NIGERIA \\ 5, CSiR - Institute of Minerals ANd MATERIALS TeChNOlogy, BHuBANESWAR-751013, INDIA.
}
E-mail addresses: ${ }^{1}$ ayinla.ik@unilorin.edu.ng, 2 baalafara@yahoo.com, ${ }^{3}$ sadisugirigisu@gmail.com, 4 bamigboyeos@yahoo.com, 5 bankimtripathy@gmail.com,6herbdul@yahoo.com,
7 samsudeen.azeez@kwasu.edu.ng

\begin{abstract}
Considering the recent focus of the Nigeria Government to grow and develop the nation's economy through the solid minerals sector reform, this study has been devoted to the kinetics of a Nigerian goethite ore by hydrochloric acid leaching for improved iron and steel industries applications. This study was performed in three different phases. In the first phase, acidic leaching of iron from a goethite ore was examined and the influence of the operating variables including: $\mathrm{HCl}$ concentration, leaching temperature, stirring speed and particle sizes was examined experimentally. The optimum condition was found to be $\mathrm{HCl}$ concentration of $1.81 \mathrm{M}$, temperature of $80^{\circ} \mathrm{C}, 200 \mathrm{rpm}$ stirring speed and particle size $0.09 \mu \mathrm{m}$ for iron in the range of investigated parameters. Under those conditions, the highest iron recovery was obtained to be $95.67 \%$. In the second phase, the dissolution kinetics of iron was evaluated by the shrinking core models. The finding reveals that diffusion through the fluid was the leaching kinetics rate controlling step of the iron. The activation energy (Ea) was found to be $14.54 \mathrm{kJmol}^{-1}$ for iron. Equation representing the leaching kinetic of iron was achieved to be $1-2 / 3 a-(1-x)^{2 / 3}=0.7272 \times e-38.29 / 8.314 \times T \times t$. The final stage of the experiment was carried out by characterizing the leached residues by $X$-ray diffractometer (XRD) and scanning electron microscopy (SEM), the result showed majorly the presence of rutile ( $\left.\mathrm{TiO}_{2}\right)$, anglesite $\left(\mathrm{PbSO}_{4}\right)$, and traces of iron-silicate face like pyrite (FeS), quartz (SiO ${ }_{2}$.
\end{abstract}

Keywords: kinetics modelling, leaching, low-grade, recovery, shrinking core

\section{INTRODUCTION}

Intensive studies for the extraction of metal from there crude ore require proper attention because of global demand for metal and some metallic compounds. Iron is an important metal that are mostly extracted from various iron ores, which include: pyrite $(\mathrm{FeS})$; hemeatite $\left(\mathrm{Fe}_{2} \mathrm{O}_{3}\right)$; magnetite $\left(\mathrm{Fe}_{3} \mathrm{O}_{4}\right)$; siderite $\left(\mathrm{FeCO}_{3}\right)$ e.t.c. Iron ore resources have been continuously exploited which have led to gradual depletion of high-grade ore and low- grade iron ore been developed as very important sources $[1,2]$.

* Corresponding author, tel: +234- $706-536-0971$ 
The high grade ferruginous quartzite iron deposit is found in the Itakpe hill. The geological proven reserve is 200 million tonnes. Since this reserve estimate is based on wide grid $(100 \mathrm{~m})$ pre-exploitation drilling need to be continuously embarked upon, for economic exploitation of the deposit. A deposit of over 6 million tonnes is also found in Ajabanoko which is $4 \mathrm{~km}$ north-west of Itakpe in Kogi State, Nigeria. The Ajabanoko deposit has similar chemical properties to that of Itakpe hill $[3,4]$. On the continental bases, Iron ore is widely distributed in all the continents. The most important source of iron ore from United State is located at Lake Superior district while that of Canada is found in four principal areas which are newfound land, Labrador trough in Quebec, the north shore of the great lake and the coast of British Columbia. Iron deposits are also found in South America, Australia and other parts of West Africa $[5,6]$.

Pyrometallurgy and hydrometallurgy are the two major conventional methods that can be adopted for extraction of iron from their ore $[7,8]$. Pyrometallurgy is consists of the thermal treatment of minerals and metallurgical ores and concentrates to bring about physical and chemical transformations in the materials to enable recovery of valuable metals [9]. This treatment may produce products which can be sold as pure metals, or intermediate compounds suitable as feed for further processing. Examples of elements extracted by pyrometallurgical processes include the oxides of less reactive elements like iron, copper, zinc, chromium, tin, and manganese [10]. Most pyrometallurgical processes require energy input to sustain the temperature at which the process takes place. The energy is usually provided in the form of combustion or from electrical heat [11].

Leaching process is the starting step of hydrometallurgical methods which are used for extraction of metals $[12,13]$. Research the other efforts of various diversities were carried out to develop the hydrometallurgical method for increasing the recovery rate of iron from its ores. Various inorganic acids have been commonly used as leaching agent in many studies [5, 14]. Aside these mentioned inorganic acids, organic acids have also been applied as leached reagent in recent years [15, 16].The intrinsic nature of chloride leach liquors resulting from the hydrometallurgical treatment of sulphide ores is rather complex. These solutions rare metals, frequently precious metals, usually contain relatively high concentrations of basic materials, as well as small contents of other [16]. Hence, this research work presents a detailed data on the chemical leaching of a Nigerian iron ore from Kaoje origin in hydrochloric acid medium. In this study, the dissolution kinetics is examined according to the shrinking core models and the best kinetics model is chosen to describe the leaching process of iron. Equally, this work is additional information supporting the recent research on a Nigerian iron-ore mineral by Baba et al., [16] which together would serve as useful information for the development of Nigerian iron and steel industries.

\section{MATERIALS AND METHODS}

\subsection{Materials}

The required ore samples were obtained from Kaoje (Gwamba mine tailings), with geographical coordinates: $11^{\circ} 11^{\prime} 0^{\prime \prime}$ North, $4^{\circ} 7^{\prime} 0^{\prime \prime}$ East and located in Bagudo, Kebbi State of Nigeria. The samples were crushed and then ground to less than $0.09 \mu \mathrm{m}$. The phases of sample were characterized by XRD (Model: XRD-6100 LABX). The main chemical composition of samples was characterized by X-ray fluorescence (Model: PHILIPS Pw 2400 SEQ) which later complimented using SEM-EDS (Model: Hitach S4700) for clarity of the morphology.

\subsection{Experimental procedure}

The dissolution process was carried out in a beaker of $500 \mathrm{ml}$, which heated on a hot plate, equipped with a digital controlled magnetic stirrer and a thermometer for temperature control. A series of hydrochloric acid solution with concentration from 0.5 to $2.26 \mathrm{M}$ were prepared as leaching agent and put into the beaker. According to the desired liquid to solid (L/S) ratio, $2 \mathrm{~g}$ of solid was added into the hydrochloric acid solution. Then solutions were mixed using a magnetic stirrer with varying stirring speed of (200-300 rpm) at temperature ranges from (55$80^{\circ} \mathrm{C}$ ). When the dissolution process finished, the sample was filtered and the liquid phase was analyzed with atom absorption spectroscopy (AAS) (model: 230ATS), for the content of iron. The leaching rate of iron was calculated according to the following formula:

$$
\mathrm{R}=\frac{c_{m}}{c_{o}} \mathrm{~V} \times 100
$$

Where $R$ is the leaching recovery percentage of metal $(\mathrm{Fe}) ; C_{\mathrm{m}}(\mathrm{g} / \mathrm{L})$ is the concentration of metal ion (Fe) in the leach liquor; $V(L)$ is the leach liquor volume; 
$\mathrm{C}_{0}(\%)$ is the metals content of $\mathrm{Fe}$ in oxide ore sample and $M(\mathrm{~g})$ is the mass of the Fe oxide ore.

\section{RESULTS AND DISCUSSION}

\subsection{Effect of hydrochloric acid concentration}

To investigate the influence of $\mathrm{HCl}$ concentration on the leaching rate of iron, the experiments were carried out in the leaching solutions containing different $\mathrm{HCl}$ concentrations $(0.5,1,1.5,1.81$ and 2.5 M) at temperature of $50^{\circ} \mathrm{C}$, stirring speed of $300 \mathrm{rpm}$ and $\mathrm{L} / \mathrm{S}$ ratio of $20 \mathrm{ml} / \mathrm{g}$, which the results are plotted in Figure 1.

When hydrochloric acid concentration increased from $0.5 \mathrm{M}$ to $1.81 \mathrm{M}$, the percentage of leached iron increased significantly from $45.12 \%$ to $80.22 \%$, In fact, when the concentration of $\mathrm{HCl}$ solution reaches 1.81 $\mathrm{M}$, the chloride ions are enough due to the further formation of $\mathrm{FeCl}_{2}$ and therefore the leaching rate could be over $90.92 \%$ for iron.

$$
\mathrm{FeOOH}+4 \mathrm{HCl} \rightarrow \mathrm{FeCl}_{2}+2 \mathrm{H}_{2} \mathrm{O}+\mathrm{Cl}_{2}
$$

\subsection{Effect of liquid to solid (L/S) ratio}

The phase ratio of liquid to solid is another important factor to influence the contact chance of chloride ions with iron hydroxide. These experiments were carried out in $1.81 \mathrm{M} \mathrm{HCl}$ solution for $120 \mathrm{~min}$ at $50^{\circ} \mathrm{C}$ with stirring of $200 \mathrm{rpm}$. The experimental data for different L/S ratios ranging from 10 to $25 \mathrm{ml} / \mathrm{g}$ are illustrated in Figure 2.

As observed, the recovery of iron enhanced with increasing L/S ratio from 10 to $20 \mathrm{ml} / \mathrm{g}$. However, further increase the $L / S$ ratio to $25 \mathrm{ml} / \mathrm{g}$, the leaching rate is reduced. Thus, L/S ratio of 20 is found to be optimal. According to Yuruev et al. [17], a higher L/S ratio is expected to reduce the viscosity of the slurry by facilitating better mixing, contributing to the reduction in diffusion mass transfer resistance. This phenomenon also can be understood from the mass transportation equilibrium between $\mathrm{FeO}$ and the coordination ions $\mathrm{FeCl}_{2}{ }^{+}$in the leaching solution.

\subsection{Effect of stirring speed}

The effect of stirring speed on the dissolution performance of iron samples was evaluated by regulating the stirring speed to 200,300 and 400 at $50^{\circ} \mathrm{C}, \mathrm{HCl}$ concentration of $1.81 \mathrm{M}$, and L/S ratio of 20 $\mathrm{ml} / \mathrm{g}$ (Figure 3).

Fig. 3 demonstrates that the stirring speed has an appreciable effect on the dissolution of iron. It can be seen that, after 90 min of dissolution, the leaching fraction of iron increases from 53.65 to $80.92 \%$ when the stirring speed increased from 200 to $400 \mathrm{rpm}$. It is also observed that, the stirring speed of $200 \mathrm{rpm}$ is beneficial for the extraction of iron to bring mineral particles into adequate contact with $\mathrm{HCl}$ solution.

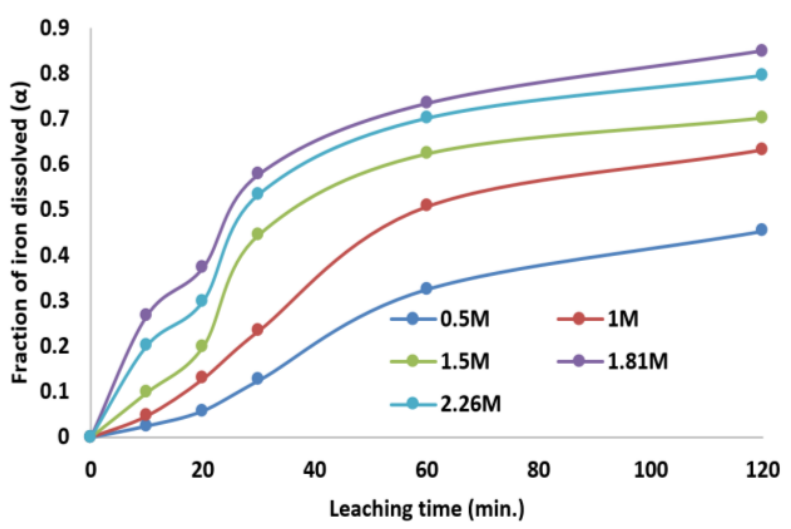

Figure 1: Effect of $\mathrm{HCl}$ concentration on the leaching recovery of iron at temperature of $50^{\circ} \mathrm{C}, \mathrm{L} / \mathrm{S}$ ratio of $20 \mathrm{ml} / \mathrm{g}$ and stirring speed of $200 \mathrm{rpm}$.

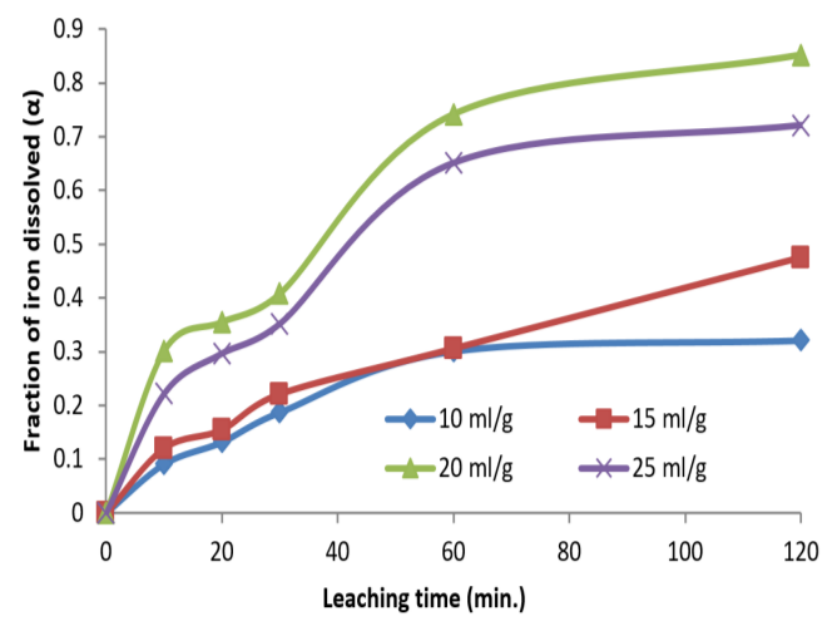

Figure 2: Effect of $L / S$ ratio on the leaching recovery of iron at temperature of $80^{\circ} \mathrm{C}, \mathrm{HCl}$ concentration of $1.81 \mathrm{M}$ and stirring speed of $200 \mathrm{rpm}$.

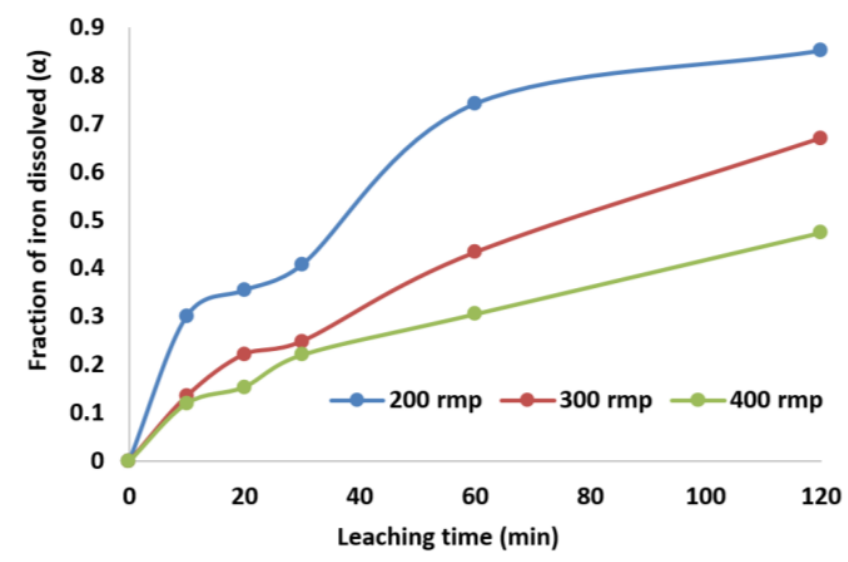

Figure 3: Effect of stirring speed on the leaching recovery of iron at temperature of $80^{\circ} \mathrm{C}, \mathrm{HCl}$ concentration of $1.18 \mathrm{M}$ and $\mathrm{L} / \mathrm{S}$ ratio of $20 \mathrm{ml} / \mathrm{g}$. 
Increasing the stirring speed will further promote reactants diffusion from bulk solution to mineral surface and improves the leaching rate accordingly $[18,19]$.

\subsection{Effect of temperature}

In order to investigate the effect of temperature on the dissolution of goethite ore, temperature was varied from $50^{\circ} \mathrm{C}$ to $90^{\circ} \mathrm{C}$ and experiments were performed at $\mathrm{HCl}$ concentration of $1.81 \mathrm{M}$ and L/S ratio of $20 \mathrm{ml} / \mathrm{g}$ with stirring speed of $200 \mathrm{rpm}$ for iron. The variation in the leaching ratio with various temperatures is shown in Figure 4.

It can be seen that, with increasing the temperature from $50^{\circ} \mathrm{C}$ to $80^{\circ} \mathrm{C}$, the leached iron increases from considerably. It is also observed that the iron leaching rate by $\mathrm{HCl}$ is only $60.32 \%$ at $50^{\circ} \mathrm{C}$, but quickly enhances to $95.52 \%$ when the temperature is increased to $80^{\circ} \mathrm{C}$. According to Vyazovkin and Lesikovich, [20], with enhancing the leaching temperature, the energy available for atomic and molecular collisions increases. In addition, mass transfer coefficient, reaction constant and diffusivity are all improved with the development of temperature. Thus, it can be found that a high enough temperature is necessary to activate the reagent and accelerate the reaction of chloride ions with iron oxides in the acidic leaching.

\subsection{Kinetic modelling}

Leaching kinetics plays an important role in the extraction of metals and compounds in an economical way. According to Wang et al. [21], it can be concluded that the leaching processing $\mathrm{HCl}$ solution involves: (i) transport of $\mathrm{HCl}$ leaching from the bulk solution to the particle surface, (ii) diffusion of $\mathrm{HCl}$ through the solid residual layer from the particle surface to the surface. The reactions occurring during the leaching process are typically heterogeneous and the relevant kinetics follows the shrinking core model which was described by [3] in detail. The following expressions can be used to describe the leaching process kinetics $[1,22]$ : where $a$ is the fractional conversion of iron, $t$ is the reaction time ( $\mathrm{min})$ and $k$ is the apparent rate constant $\left(\mathrm{min}^{-1}\right)$. The overall rate of dissolution is controlled by the slowest of these sequential steps. Values of Equations (4)-(6) versus the reaction time were plotted to determine the kinetic parameters and leaching rate control-ling step, which the results are shown in Figs. 5 and 6 . Leaching experiments were carried out at temperatures ranging from 50 to $80{ }^{\circ} \mathrm{C}$ in steps of $10 \cdot \mathrm{C}$ at $\mathrm{HCl}$ concentration of $1.4 \mathrm{M}$ and L/S ratio of $20 \mathrm{ml} / \mathrm{g}$ with a stirring speed of $200 \mathrm{rpm}$ for iron dissolution. From the slopes of the straight lines the apparent rate constants, $k$, were evaluated, which the rate constants calculated and their correlation coefficients are given in Figure 5.

For diffusion control through the fluid film:

$$
1-(1-\alpha)^{2 / 3}=k \times t
$$

For solid product diffusion control:

$$
1-3(1-\alpha)^{2 / 3}+2(1-\alpha)=k \times t
$$

For surface chemical reaction control:

$$
1-(1-\alpha)^{1 / 3}=k \times t
$$

Where $a$ is the fractional conversion of iron in the leached liquor, $t$ is the reaction time $(\mathrm{min})$ and $k$ is the apparent rate constant $\left(\mathrm{min}^{-1}\right)$.

The overall rate of dissolution is controlled by the slowest of these sequential steps. Values of these equations [(equation 3-5)] versus the reaction time were plotted to determine the kinetic parameters and leaching rate controlling step. The obtained results were presented in Figures. 5 and 6. From the slopes of the straight lines the apparent rate constants, $k$, were evaluated, which the rate constants calculated and the correlation coefficient is given in Figures 5 .

As seen, the highest $R^{2}$ values obtained as compare to other shrinking models used signifies that the diffusion control mechanism is best fitted for the reaction.

Additionally, in leaching processes, dissolution rate directly depends on the activation energy, which can be calculated based on the Arrhenius equation ( $k=$ $\left.A \times e^{-E a / R T}\right)$. Based on the Arrhenius activation energy theory, Arrhenius equation was plotted as In $(K)$ vs. $(1 / T)$ for each temperature and the activation energies were calculated from the slopes of straight lines where the slope is $-\mathrm{Ea} / R$ (Figure 6).

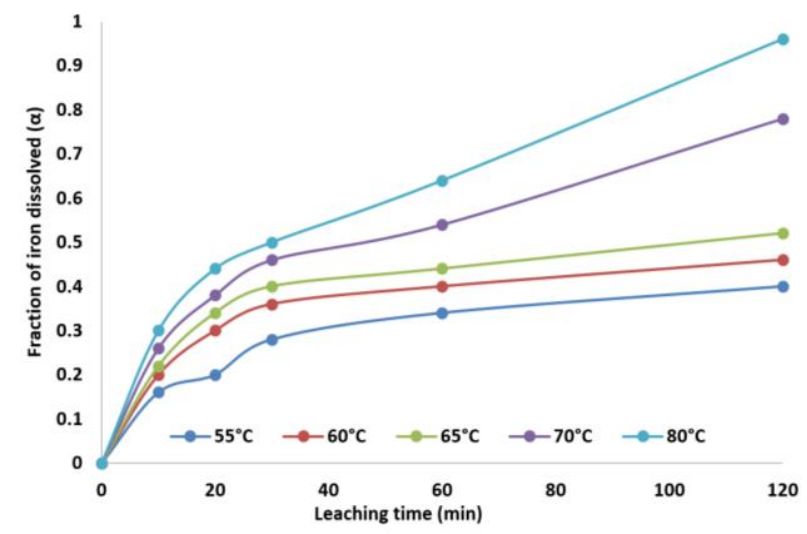

Figure 4: Effect of temperature on the leaching recovery of iron at $\mathrm{HCl}$ concentration of $1.81 \mathrm{M}$, stirring speed of $200 \mathrm{rpm}$ and $\mathrm{L} / \mathrm{S}$ ratio of $20 \mathrm{ml} / \mathrm{g}$. 


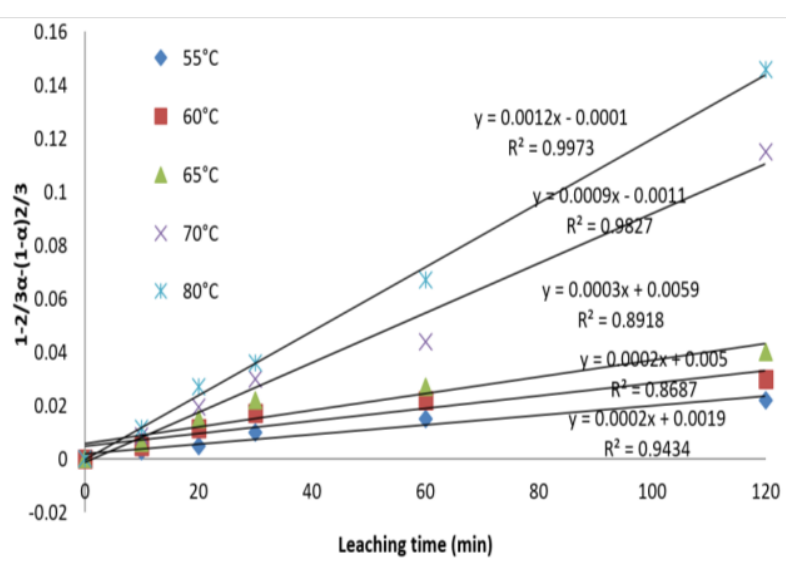

Figure 5: Plot of the diffusion controlled shrinking core models vs. leaching time at different temperatures for the dissolution reactions of iron with $\mathrm{HCl}$ solution.

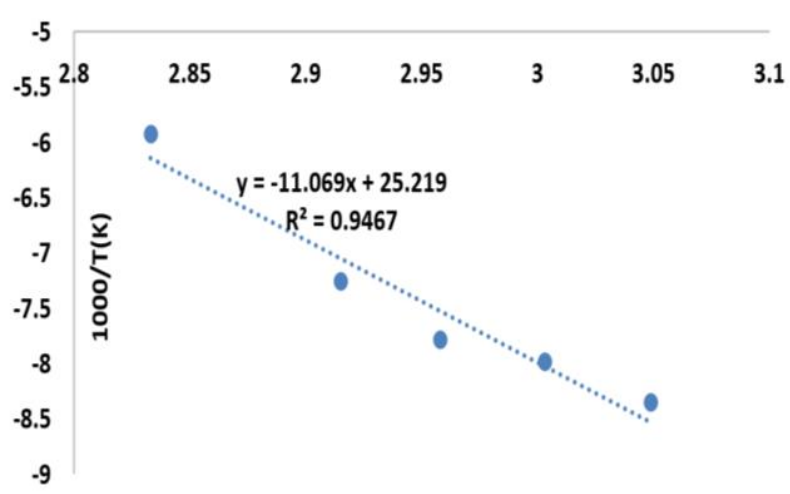

Figure 6: Arrhenius plot for leaching of iron using $\mathrm{HCl}$ solution based on the liquid film diffusion model

$$
\left(1-2 / 3 a-(1-a)^{2 / 3}\right) \text {. }
$$

The values of activation energies calculated from Arrhenius plot gave $32.23 \mathrm{~kJ} / \mathrm{mol}$. It has been previously stated that the typical activation energy for a chemically controlled process is greater than 40 $\mathrm{kJ} / \mathrm{mol}$, while the activation energy of a diffusion controlled process is usually below $40 \mathrm{~kJ} / \mathrm{mol}$ [23-27]. According to this obtained value, it can be concluded that leaching process of iron from Kaoje, geothite ore using hydrochloric acid is controlled by diffusion process. Consequently, the equations representing the kinetics of leaching process of iron can be expressed as according to Equation 6

$1-\frac{2}{3} \alpha-(1-\alpha)^{\frac{2}{3}}=0.7272 \times e^{-32.23 / 8.314} \times t$

\subsection{Morphology of the leached residues}

The leached residue obtained from the leaching process was examined for surface morphology and elemental distribution using XRD and SEM-EDS. The XRD spectral is presented in Figure 7.

The identify peaks in Figure $7 \mathrm{~B}$ shows total eradication of peaks attributed to irons with only siliceous compound remaining after leaching. This was compared with XRD spectral of goethite sample under investigation (Figure $7 \mathrm{~A}$ ) to ascertain the efficient nature of the leachant used in this study.

The SEM analysis of the undissolved residue ($19.8 \%)$ at optimal condition (1.81 $\mathrm{M} \mathrm{HCl}$, temperature $80^{\circ} \mathrm{C}, 120 \mathrm{~min}$ ) depicted in (Figure 8), shows scarcely dispersed small grain-sized dark patches which could be attributed to silicieous compound on the surface of the ore. This is as a result of high selective leaching ability of the ore in chloride media confirm to this claim as peaks corresponding to iron are totally absent, indicating complete dissolution under the optimized conditions. The predominant components of the residue as examined by EDS include silica (39.38\%) and oxygen $(60.62 \%)$.

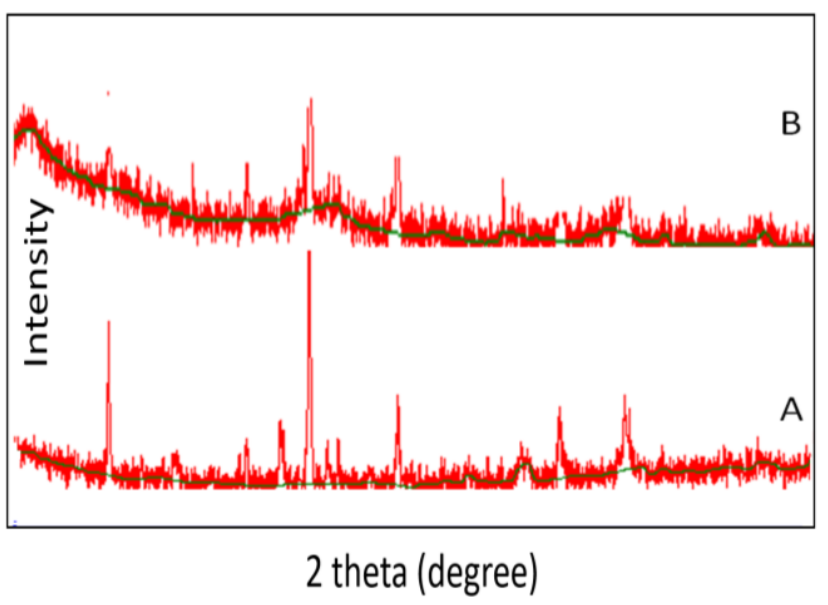

Figure 7: XRD spectral of goethite ore: (A) Raw goethite $(B)$ leached geothite

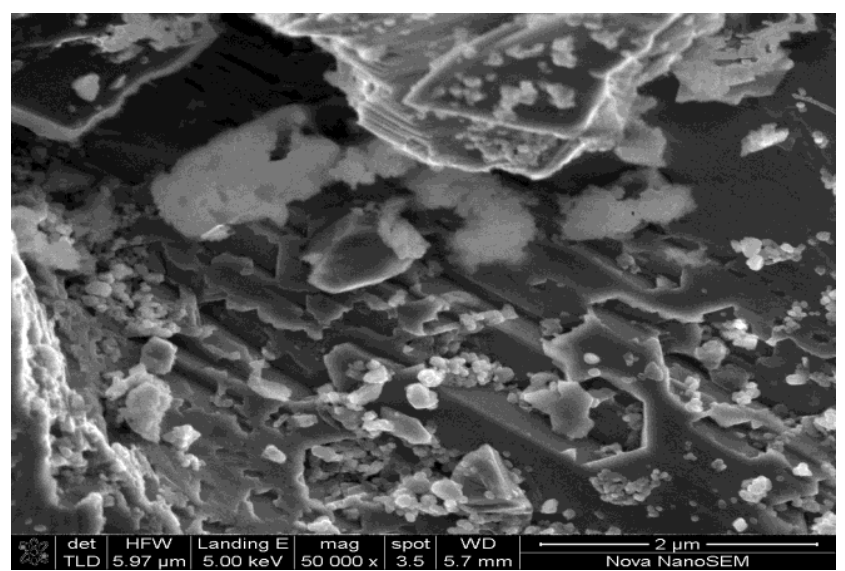

Figure 8: SEM Image of leached residues showing silicious phases

Vol. 39, No. 3, July 2020

Nigerian Journal of Technology, 


\section{CONCLUSION}

On the basis of the results of this investigation, the following conclusions can be drawn: (i) Increasing the concentration of $\mathrm{HCl}$ leads to increase in the amount of iron ore dissolved at a particular time. Hence, the rate is proportional to the $\mathrm{H}^{+}$ion concentration(ii) The dissolution rates are inversely proportional to the average diameter of the particles. (iii) The dissolution kinetics follows a shrinking core model with the diffusion controlled reaction as the rate controlling step and activation energy of $38.29 \mathrm{~kJ} / \mathrm{mole}$ is obtained for the process. The equations representing the kinetics of leaching process of iron can be expressed as according to Equation: $1-2 / 3 a-(1-x)^{2 / 3}=0.7272 \times$ e-38.29/8.314 $\times$ T $\times$ t. Consequently, the residue morphological studies showed that there is majorly Quartz $\left(\mathrm{SiO}_{2}\right)$. Based on the lower activation energy obtained in this study, the design is therefore recommended for further scaling up process to assist the iron and steel industries.

\section{ACKNOWLEDGEMENT}

The authors thank Aladere and co Mining, Alapa District, Asa Local Government of Kwara State for giving the insight on the location of the iron ore deposit in Kaoje and also we acknowledge the financial support of Mr. M.A. Adegoke for ore characterisation at Centre for Imaging in South Africa.

\section{REFERENCES}

[1] Abdel-Aal, E.A. "Kinetics of sulphuric acid leaching of low grade zinc silicate ore". Hydrometallurgy, 55, 2000, 247-254

[2] Gaviria, J. P., Bohe, A., Pasquevich, A. and Pasquevich, D. M. "Hematite to magnetite reduction monitored by mossbaur spectroscopy and X-ray diffraction". Physica, 389, 2007, 198-201.

[3] Antonijevi, M. M., Jankovi Z. D, Dimitrijivi M. D. "Kinetics of chaloopyrite dissolution by hydrogen peroxide in sulphuric acid". Hydrometallurgy, Vol. 71, (3-4), 2004, 329334.

[4] Baba, A. A., Adekola F.A., Lawal A.J. "Investigation of chemical and microbial leaching of iron ore in sulphuric acid", J. Appl. Sci. Environ. Manage, Vol. 11 (1), 2007, 39-44.

[5] Baba, A. A.,Adekola F. A.,Folashade A. O. "Quantitative leaching of a Nigerian iron ore in hydrochloric acid". J. App/ Sci. Environ. Mange, Vol. 9 ( 3), 2005, 15 - 20.

[6] Badende, T.I, "History of iron and the challenges in mining', Journal of National iron ore Mining Company Limited, Itakpe, Nigeria 2001, 3-9.

[7] Piotrowski, K., Mondal, K., Wiltowski, T., Dydo, P. and Rizeg, G. "Topochemical approach of kinetics of the reduction of hematite to wustite". Chemical Engineering Journal, Vol.131, 2007, 73-82.

[8] Seyed, M., Seyed G., Asghar A. "Alkaline leaching of lead and zinc by sodium hydroxide". $J$. Mater. Res. Tech. Vol.7(2), 2018, 118-125

[9] Ru-Quan, L., Shou, Y., Fe-Sheng, Y. and JiCheng, $\mathrm{H}$. "Kinetics of oxidation reaction for magnetite pellets". Journal of Iron and Steel research, International, Vol.20, 2013,16-20.

[10] Xiao-Hui, F., Min, G., Tao, J., Li-Shung, Y. And Xu-Ling, $C$. "Influence of flux additives on iron ore oxidized pellets". J. Cent. South Univ. Technol., Vol. 17, 2010, 732-737.

[11] Ju S., Motang T., Shenghai Y., Yingia I. "Dissolution kinetics of sinthsonite ore in ammonium chloride solution". Hydrometallurgy, 80, 2005, 67-74

[12] Hursit, M., Lacin O., Sarac H "Dissolution kinetics of smihsonit ore as an alternative zinc source with an organic leach reagent". J. Taiwan Inst. Chem. Eng. Vol.40, 2009, 6-12

[13] Ruixiang, W, Motang T., Shenghai Y., Wenhai Z., Chaobo $\mathrm{T}$., Jing $\mathrm{H}$. "leaching kinetics of low grade zinc oxide ore in $\mathrm{NH}_{3}-\mathrm{NH}_{4} \mathrm{Cl}-\mathrm{H}_{2} \mathrm{O}$ system". J.Cent. South.Univ.Tech., Vol.15, 2008, 679-683

[14] Dutrizac, J. E.; Hiskey J. B.; Warren G. W. Hydrometallurgy - fundamentals, technology and innovation. Society for mining, metallurgy and Exploration Littleton, Colorado, U.S.A., 1993, 908-929.

[15] Irannajad, M., Mashkini M., Azadmehr A, "Leaching of zinc from low grade oxide ore using organic acid". Physicochem. Probl. Miner Processing. Vol.49, 2013, 547-555.

[16] Larba, R., Boukerche I., Alane N., Habbache N., Djerad S., Tifont L. "Citric acid as an alternative lixiviant for zinc oxide dissolution". Hydrometallurgy, Vol. 134-135, 2013, 117- 123

[17] Parid K.M. and Das N.N. "Reductive dissolution of hematite in hydrochloric acid medium by inorganic and organic reductants" . Indian Journal of Engineering and material, Vol.5 (7), 1996, 236-240 
[18] Yurev, B. P. and Spirin, N. A. "Oxidation of iron ore pellets". Steel in translation,Vol. 41, 2000, 400-412

[19] Liu C, Hu Y, Cao X. "Substituent effects in kaolinite flotationusing dodecyl tertiary amines". Miner Eng , Vol. 22(9-10), 2009, 84952 ,

[20] Vyazovkin, S. and Wight, C. A. "Isothermal and non-isothermal kinetics of thermally activated reactions of solids". International reviews in physical chemistry, Vol.17(3), 1998, 407-433.

[21] Vyazovkin, S. V and Lesnikovich, A. I. "Estimation of the pre-exponential factor in the isoconversional calculation of effective kinetic parameters". Thermochemica Acta, Vol.128, 1988,297-300.

[22] Barati, M.(2008). Dynamic simulation of pellet in duration in straight-grate system. International Journal of Minerals, 30-39.
[23] Ayinla I. K. "Development of Extraction Methods and Preparation of some Industrial Chromium Compounds from a Nigerian chromite ore". Ph.D thesis, Department of Chemistry University of Ilorin, Ilorin -Nigeria. 2019, pp 453

[24] Encyclopedia of Analytical Science, Academic Press, London, 4, 1995, 2369-2372.

[25] Kirk-Othmer Encyclopedia of Chem. Tech. John Willey \& Sons. Inc., New York, 12, 1996, 12-23

[26] Vyazovkin, S., Chrissafis, K., Koga, N., Lorenzo, M. L. D., Pijolet, M., Roduit, B., Sbirrazzuoli, N. and Sunol, J. J. "Kinetics Committee recommendations for collecting experimental thermal analysis data for kinetic computations". Thermochemica Acta, Vol. 590, 2014, 1-23.

[27] John, H. Y.; Wadsworth M. E. "Rate process of extractive Metallurgy Inc" ; Plenum, New York, $1979,133$. 